\title{
Lumbosacral Transitional Vertebrae in Low Back Pain Population
}

\section{Bekir Yavuz Uçar ${ }^{1 *}$, Demet Erdoğan Uçar², Mehmet Bulut', Ibrahim Azboy' and Abdullah Demirtaş ${ }^{1}$}

${ }^{1}$ Department of Orthopaedics and Traumatology, Dicle University, Diyarbakir, Turkey

${ }^{2}$ Department of Physical Treatment and Rehabilitation, Dicle University, Diyarbakir, Turkey

\section{Abstract}

Background: The relationship between lumbosacral transitional vertebrae and low back pain is not clear. This controversy has been quite intriguing and has been the stimulus for carrying out this present study. The aim of this study was to determine, by plain radiography, if there is a relationship between lumbosacral transitional vertebrae and low back pain.

Material and methods: Five hundred lumbosacral radiographs of low back pain patients were examined. Dysplastic transverse process was classified according to the Castellvi radiographic classification system. The incidence of lumbosacral transitional vertebra in patients with low back pain was reported, and the patients who had anomaly were compared according to gender and age.

Results: Of these patients, 118 were classified as positive for transitional lumbosacral vertebra, resulted in an incidence of $23.6 \%$. The most common anatomical variant was Castellvi Type IA (6.8\%). No statistically significant difference was found between these two age groups according to incidence of lumbosacral transitional vertebra $(p=0.207)$. There were no statistically significant differences between men and women who had anomaly $(p=0.289)$. Higher incidences of Type IB and Type IIB were found in men, but those results were not statistically significant $(p=0.112, p=0.514)$ when compared with the female group.

Conclusion: Based on our data, we conclude that lumbosacral transitional segments are common in the low back pain population. But no relationship found between age and genders.

Keywords: Lumbosacral transitional vertebra; Low back pain; Castellvi classification; Sacralization; Lumbarization

\section{Introduction}

Numerous causes have been attributed to low back pain (LBP). A long list exists, but the enlistment of lumbosacral transitional vertebra (LSTV) as one of the causes has resulted in a lot of controversy. LSTV is a congenital vertebral anomaly of the lumbosacral spine, involving the lumbarization of $\mathrm{S} 1$ (non-fusion between the first two sacral segments) and sacralization of the fifth lumbar vertebra (fusion between L5 and the first sacral segment) [1]. This alteration may contribute to incorrect identification of a vertebral segment.

Several studies have described the occurrence of this anomaly in a back pain population [2-7]. Some authors have stated that LSTV is incidentally diagnosed and has no clinical impact $[7,8]$, whereas others claim that this anomaly may predispose patients to certain clinical disorders $[9,10]$. This controversy has been quite intriguing and has been the stimulus for carrying out this present study. The intention was to examine in detail the incidence of this anomaly in the LBP population. Our study aimed to use the incidence of this congenital anomaly to establish a relationship between it and LBP.

\section{Material and Methods}

After institution review board approval from the ethical committee of Dicle University Medical School for this prospective study, 500 lumbosacral radiographs of LBP orthopaedic out-patients were collected over a one-year period. The ages ranged between 16 years and 73 years, and both sexes were involved. All the patients gave the informed consent prior being included into the study. Frontal (AP) and lateral lumbosacral regions were evaluated. The radiographs were examined, and data was collected and analyzed. We included only low back pain patients. These patients were treated as outpatients. They did not require hospitalization for previous LBP episodes. Exclusion criteria consisted of the radiculopathies, degenerated levels and any radiologic evidence of previous lumbosacral surgery that would obstruct our measurements. Severity of back pain was not significant for this study. Our aim was to describe any relationship about LSTV in the localised low back pain outpatients. Because of that severity of pain has not been queried. A total of 500 lumbosacral films were examined and identified as being adequate for measurement of the desired parameters. Data collection consisted of the subject's age at the time of imaging, gender, number of lumbar vertebral bodies, and bilateral height measurement of the lowest lumbar transverse process. Three orthopedic spine fellows performed all the measurements, using a systemized approach to decrease variability; in addition, consultations between reviewers took place. Digital films were downloaded to an imaging processing program for standardization of the measurements. Subjects without transverse process dysplasia were classified as normal (Type 0), and those with dysplastic transverse process were classified according to the Castellvi radiographic classification system11 (Table 1). The incidence of LSTV in patients with LBP was reported, and the patients who had LSTV were compared according to gender and age.

\section{Statistical Analysis}

Statistically significant differences were evaluated by using contingency tables with Fisher's exact test for categorical variables. This test was used to compare statistically the differences between men and women with LSTV. In addition, it was used to compare patients older

*Corresponding author: Bekir Yavuz Uçar, Assistant Professor, Dicle University Medical Faculty, Diyarbakir, Turkey, Tel: 0090 4122488001; Fax: 00904122488111 E-mail: drbyucar@yahoo.com

Received October 29, 2012; Accepted November 26, 2012; Published November 28, 2012

Citation: Uçar BY, Uçar DE, Bulut M, Azboy I, Demirtaş A (2013) Lumbosacral Transitional Vertebrae in Low Back Pain Population. J Spine 2:125. doi:10.4172/2165-7939.1000125

Copyright: (C) 2013 Uçar BY, et al. This is an open-access article distributed under the terms of the Creative Commons Attribution License, which permits unrestricted use, distribution, and reproduction in any medium, provided the original author and source are credited. 
Citation: Uçar BY, Uçar DE, Bulut M, Azboy İ, Demirtaş A (2013) Lumbosacral Transitional Vertebrae in Low Back Pain Population. J Spine 2:125. doi:10.4172/2165-7939.1000125

Page 2 of 3

than 35 years with younger patients. Statistical significance was set at $\mathrm{p}<0.05$.

\section{Results}

Five hundred patients, 281 women and 219 men, were identified as eligible for the study; the average age was $39.03 \pm 15.9$ years $(16-73$ years). Of these patients, 118 were classified as positive for transitional lumbosacral vertebra, with a gender distribution of 61 (21.71\%) women and $57(26.03 \%)$ men. These numbers resulted in an incidence of $23.6 \%$, and a ratio of 1:3.2 (approximately one case of LSTV to every three normal patients with normal spines presented with LBP) (Table 2). Of the total number of males (219) seen, 57 (26\%) had LSTV and 162 (74\%) had normal spines. This shows that the ratio of incidence of LSTV males to normal males is $1: 2.84$. Of the 281 females seen, $61(21.7 \%)$ had LSTV and $220(78.3 \%)$ had normal spines, for a ratio of incidence of LSTV females to normal females of 1:3.6. Of the total number of patients (500) seen, $12(2.4 \%)$ had lumbarization; sacralization (106 patients, $21.2 \%$ ) is the more common LSTV (Table 2). The incidence ratio of sacralization to lumbarization is approximately 9.8:1.

According to sacralization classification, the most common anatomical variant was Castellvi Type IA (6.8\%), followed by Type IB (5.4\%), Type IIA (1.6\%), Type IIB (1.8\%), Type IIIA (1.4\%), Type IIIB (3.4\%), and Type IV (0.8\%) (Figure 1).

There were $262(52.4 \%)$ patients older than 35 years old and 238 (47.6\%) younger patients. Sixty-eight of the older patients had LSTV, compared with 50 of the younger patients. No statistically significant difference was found between these two age groups according to incidence of LSTV ( $\mathrm{p}=0.207)$ (Table 3).

There were no statistically significant differences between men and women who had LSTV ( $\mathrm{p}=0.289$ ) (Table 4). Higher incidences of Type IB and Type IIB were found in men, but those results were not statistically significant $(\mathrm{p}=0.112, \mathrm{p}=0.514)$ when compared with the female group (Table 4).

\section{Discussion}

The incidence of our lumbar spine patients who had a transitional

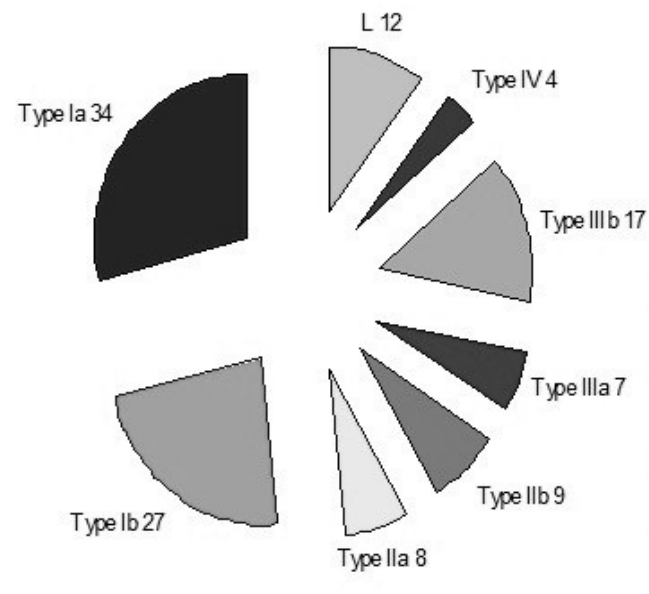

Type la

$\square$ Type $\mathrm{lb}$

$\square$ Type lla

$\square$ Type $l 1 \mathrm{~b}$

Type lla

$\square$ Type $\| l b$

Type IV

$\square \mathrm{L}$

L: Lumbarization

Figure 1: Numbers of types according to Castellvi classification.
Type la A unilateral TP height greater than or equal to $19 \mathrm{~mm}$

Type lb Both processes height greater than or equal to $19 \mathrm{~mm}$

Type lla Presence of unilateral articulation between the TP and the sacrum

Type Ilb Presence of bilateral articulation between the TP and the sacrum

Type Illa Unilateral fusion of the TP and the sacrum

Type Illb Bilateral fusion of the TP and the sacrum Type IV Unilateral typell transition (articulation) with a typelll (fusion) on the

TP: lowest lumbar transverse process

Table 1: Castellvi radiographic classification system of sacralization.

\begin{tabular}{|l|l|l|l|l|}
\hline & $\begin{array}{l}\text { Mean age } \\
\text { (years) }\end{array}$ & $\begin{array}{l}\text { Incidence of } \\
\text { LSTV (\%) }\end{array}$ & $\begin{array}{l}\text { Incidence of } \\
\text { Sacralization (\%) }\end{array}$ & $\begin{array}{l}\text { Incidence of } \\
\text { Lumbarization(\%) }\end{array}$ \\
\hline All Patients & $39.03 \pm 15.9$ & 23.6 & 21.2 & 2.4 \\
\hline Male Patients & $35.72 \pm 15.16$ & 26.03 & 23.73 & 2.3 \\
\hline Female Patients & $41.60 \pm 16.01$ & 21.71 & 19.21 & 2.5 \\
\hline
\end{tabular}

Table 2: Mean age and incidences of the patients.

\begin{tabular}{|c|c|c|c|}
\hline & $\begin{array}{l}\text { Older than } \\
35 \text { years old Patients } \\
(\mathrm{n} / \%)\end{array}$ & $\begin{array}{l}\text { Younger than } \\
35 \text { years old Patients } \\
(\mathrm{n} / \%)\end{array}$ & $P$ value ${ }^{*}$ \\
\hline LSTV & $68 / 26$ & $50 / 21$ & 0.207 \\
\hline Type la & $23 / 8.8$ & $11 / 4.6$ & 0.076 \\
\hline Type lb & $14 / 5.3$ & $13 / 5.5$ & 1 \\
\hline Type Ila & $4 / 1.5$ & $\begin{array}{lll}4 & 1 & 1.7\end{array}$ & 1 \\
\hline Type Ilb & $\begin{array}{lll}5 & 1.9\end{array}$ & $\begin{array}{lll}4 & / & 1.7\end{array}$ & 1 \\
\hline Type IIla & $\begin{array}{lll}5 & / & 1.9\end{array}$ & $\begin{array}{lll}2 & 0.8\end{array}$ & 0.454 \\
\hline Type IIIb & $12 / 4.6$ & $5 / 2.1$ & 0.145 \\
\hline Type IV & $\begin{array}{lll}2 & / & 0.8\end{array}$ & $\begin{array}{lll}2 & / & 0.8\end{array}$ & 1 \\
\hline L & $\begin{array}{lll}3 & 1 & 1.2\end{array}$ & $\begin{array}{lll}9 & 3.8\end{array}$ & 0.077 \\
\hline
\end{tabular}

LSTV : Lumbosacral Transitional Vertebra

$\mathrm{L}$ : Lumbarization

* : Fisher's exact test

Table 3: Comparison the LSTV according to the age.

\begin{tabular}{|l|l|l|l|}
\hline & $\begin{array}{l}\text { Male Patients } \\
(\mathrm{n} / \%)\end{array}$ & $\begin{array}{l}\text { Female Patients } \\
(\mathrm{n} / \%)\end{array}$ & P value* $^{*}$ \\
\hline LSTV & $57 / 26$ & $61 / 21.7$ & 0.289 \\
\hline Type la & $17 / 7.8$ & $17 / 6.1$ & 0.478 \\
\hline Type Ib & $16 / 7.3$ & $11 / 3.9$ & 0.112 \\
\hline Type Ila & $4 / 1.8$ & $4 / 1.4$ & 0.734 \\
\hline Type IIb & $5 / 2.3$ & $4 / 1.4$ & 0.514 \\
\hline Type IIla & $1 / 20.5$ & $6 / 2.1$ & 0.143 \\
\hline Type IIlb & $8 / 3.7$ & $9 / 3.2$ & 0.808 \\
\hline Type IV & $1 / 20.5$ & $3 / 1.1$ & 0.635 \\
\hline L & $5 / 2.3$ & $7 / 2.5$ & 1 \\
\hline
\end{tabular}

LSTV : Lumbosacral Transitional Vertebra

$\mathrm{L}$ : Lumbarization

* : Fisher's exact test

Table 4: Comparison the LSTV according to the gender.

vertebra was $23.6 \%$. This supports our belief that the alteration in mechanics caused by a transitional vertebra may at times contribute to pain generation. Our percentage of transitional vertebra was exactly equal to the findings of Luoma et al. and Castellvi et al. [5,11]. Many of the authors with lower estimations used more stringent criteria to count a vertebra as transitional, and other authors did not clearly state all of the inclusion criteria. While Elster [12] and Hsieh et al. [13] reported prevalence as low as 7\% and 5.9\%, respectively, and Delport et al. [14] observed a rate of $30 \%$, they were based on articulation or fusion of at least one transverse process and presence of an intervertebral disc caudal to the transitional segment, ultimately failing to recognize our most common subtype-Type I. This leaves the current estimates of 
those with a transitional vertebra in the range of $6 \%-37 \%$ in those seeking healthcare for low back pain, either slightly or significantly higher than the $4 \%-36 \%$ commonly reported as the number with a transitional vertebra in the general population. This large fluctuation in estimates for the general population amplifies the difficulties in determining the significance of the percentage that we found in our patients.

Our study found an incidence rate for lumbosacral transitional state in the low back pain population and defined the occurrence rate for each subtype of the Castellvi radiographic classification system. In comparison, Castellvi et al. [11] reported a $30 \%$ prevalence on his low back pain population, stating higher rates for Types IV, IIIB, and both Types II. His biggest cohort came from the Type II (38.3\%), whereas ours was largely from Type I (IA and IB) (51.7\%). Apazidis et al. [15] found $35.6 \%$ prevalence of LSTV in their studies of 211 lumbar spine subjects who had no pain. Their most commonly found pathology was Type IA (14.7\%), as in our study.

There were no statistically significant differences between men and women who had LSTV in our study. Mostly in the literatures LSTV is predominant in males. Eyo et al. [16] reported higher rate in males. In their study, despite the higher number of females present in the sample population, more males were seen to have LSTV and also presented with sacralization, which causes more severe LBP. Nardo et al. [17] reported a prevalence of LSTV with a higher rate in men than in women. In our study, higher incidences of Type IB and Type IIB were found in men, but those results were not statistically significant.

We described 68 of the older patients had LSTV, compared with 50 of the younger patients. No statistically significant difference was found between these two age groups according to incidence of LSTV. Quinlan et al. [2] found the total incidence of LSTV to be $4.6 \%$, while the frequency was $11.4 \%$ in the under 30 age group. These authors claimed that the transitional vertebra should be kept in mind when low back pain is apparent in young individuals. Epstein et al. [18] found a higher incidence of transitional vertebra in teenagers suffering from LBP. In our study, higher incidences were seen in older patients, but no statistically significant differences were found between age groups.

\section{Conclusion}

This study focuses on the evaluation of radiographic morphology of sacra bearing accessory articulations with the L5 vertebrae in the low back pain population. In this study, we wanted to find the incidence of this pathology and the relationship between the ages and genders. Based on our data, we conclude that lumbosacral transitional segments are common in the low back pain population. But no relationship found between age and genders.

\section{References}

1. Konin GP, Walz DM (2010) Lumbosacral transitional vertebrae: classification, imaging findings, and clinical relevance. AJNR Am J Neuroradiol 31: 17781786.

2. Quinlan JF, Duke D, Eustace S (2006) Bertolotti's syndrome. A cause of back pain in young people. J Bone Joint Surg Br 88: 1183-1186.
3. Frymoyer JW, Newberg A, Pope MH, Wilder DG, Clements J, et al. (1984) Spine radiographs in patients with low-back pain. An epidemiological study in men. J Bone Joint Surg Am 66: 1048-1055.

4. Dai L (1999) Lumbosacral transitional vertebrae and low back pain. Bull Hosp Jt Dis 58: 191-193.

5. Luoma K, Vehmas T, Raininko R, Luukkonen R, Riihimäki H (2004) Lumbosacral transitional vertebra: relation to disc degeneration and low back pain. Spine (Phila Pa 1976) 29: 200-205.

6. Stinchfield FE, Sinton WA (1955) Clinical significance of the transitional lumbosacral vertebra; relationship to back pain, disk disease, and sciatica. J Am Med Assoc 157: 1107-1109.

7. van Tulder MW, Assendelft WJ, Koes BW, Bouter LM (1997) Spinal radiographic findings and nonspecific low back pain. A systematic review of observational studies. Spine (Phila Pa 1976) 22: 427-434.

8. Paajanen H, Erkintalo M, Kuusela T, Dahlstrom S, Kormano M (1989) Magnetic resonance study of disc degeneration in young low-back pain patients. Spine (Phila Pa 1976) 14: 982-985.

9. Chang HS, Nakagawa H (2004) Altered function of lumbar nerve roots in patients with transitional lumbosacral vertebrae. Spine (Phila Pa 1976) 29: 1632-1635.

10. Wigh RE, Anthony HF Jr (1981) Transitional lumbosacral discs. probability of herniation. Spine (Phila Pa 1976) 6: 168-171.

11. Castellvi AE, Goldstein LA, Chan DP (1984) Lumbosacral transitional vertebrae and their relationship with lumbar extradural defects. Spine (Phila Pa 1976) 9: 493-495.

12. Elster AD (1989) Bertolotti's syndrome revisited. Transitional vertebrae of the lumbar spine. Spine (Phila Pa 1976) 14: 1373-1377.

13. Hsieh CY, Vanderford JD, Moreau SR, Prong T (2000) Lumbosacral transitional segments: classification, prevalence, and effect on disk height. J Manipulative Physiol Ther 23: 483-489.

14. Delport EG, Cucuzzella TR, Kim N, Marley J, Pruitt C, et al. (2006) Lumbosacral transitional vertebrae: incidence in a consecutive patient series. Pain Physician 9: 53-56.

15. Apazidis A, Ricart PA, Diefenbach CM, Spivak JM (2011) The prevalence of transitional vertebrae in the lumbar spine. Spine J 11: 858-862.

16. Eyo MU, Olofin A, Noronha C, Okanlawon A (2001) Incidence of lumbosacral transitional vertebrae in low back pain patients. West African Journal of Radiology 8.

17. Nardo L, Alizai H, Virayavanich W, Liu F, Hernandez A, et al. (2012) Lumbosacral transitional vertebrae: association with low back pain. Radiology 265: 497-503.

18. Epstein JA, Epstein NE, Marc J, Rosenthal AD, Lavine LS (1984) Lumbar intervertebral disk herniation in teenage children: recognition and management of associated anomalies. Spine (Phila Pa 1976) 9: 427-432. 